Kansas State University Libraries

New Prairie Press

\title{
APPLICATIONS OF ESTIMABLE FUNCTIONS IN AGRICULTURAL RESEARCH WITH SPECIAL EMPHASIS ON THE GLM PROCEDURE OF SAS.
}
L. Munyakazi
R. L. Hintz
B. D. Selby

Follow this and additional works at: https://newprairiepress.org/agstatconference

Part of the Agriculture Commons, and the Applied Statistics Commons

\section{(c) $(1) \Theta \Theta$}

This work is licensed under a Creative Commons Attribution-Noncommercial-No Derivative Works 4.0 License.

\section{Recommended Citation}

Munyakazi, L.; Hintz, R. L.; and Selby, B. D. (1994). "APPLICATIONS OF ESTIMABLE FUNCTIONS IN AGRICULTURAL RESEARCH WITH SPECIAL EMPHASIS ON THE GLM PROCEDURE OF SAS.," Conference on Applied Statistics in Agriculture. https://doi.org/10.4148/2475-7772.1365

This is brought to you for free and open access by the Conferences at New Prairie Press. It has been accepted for inclusion in Conference on Applied Statistics in Agriculture by an authorized administrator of New Prairie Press. For more information, please contact cads@k-state.edu. 


\title{
APPLICATIONS OF ESTIMABLE FUNCTIONS IN AGRICULTURAL RESEARCH WITH SPECIAL EMPHASIS ON THE GLM PROCEDURE OF SAS.
}

\author{
L.Munyakazi ,R.L. Hintz, and B.D. Selby \\ Monsanto Company
}

\begin{abstract}
An understanding of estimable functions is essential when using an overparameterized linear model. The most attractive features of these functions are their invariance property to the solution vector and their wide range of practical applications in agricultural research. This study reviews some of the ways that estimable functions can be used by the agricultural scientist.
\end{abstract}

(KEY WORDS: Estimable function, regression coefficients, carryover, direct and permanent effects, sum-to-zero and set-to-zero restrictions).

\section{Introduction}

Many agricultural experiments that are originally designed to generate balanced data result in collected data that are unbalanced. It is also the case that many experiments are intrinsically unbalanced due to research or financial constraints placed on data collection. Because the majority of agricultural researchers use linear models for parameter estimation and hypothesis testing of data that are often unbalanced, it is necessary that a knowledge of the use of estimable functions is cultivated.

The use of estimable functions is the main ingredient in overspecified or overparameterized linear model parameter estimation and hypothesis testing. From a well defined linear model, various statistics can be derived from the model form of estimable function, and the appropriate use of corresponding coefficients.

The definition of an estimable function is based on its invariance property to the solution vector. From Searle (1987) any function $k^{\prime} \beta$, i.e, $k=$ any vector and $\beta=v e c t o r$ of parameters, for which $k^{\prime} \beta^{\circ}$, i.e, $\beta^{\circ}=$ solution vector of parameter estimates, is invariant to $\beta^{\circ}$ is said to be an estimable function; and is estimated by $k^{\prime} \beta^{\circ}$. Consequently, it is expected that scientists analyzing the same data for the same purpose of estimation and hypothesis testing should obtain identical results regardless the generalized inverse they use.

It is the purpose of this paper to show that estimable functions can be used in many different applications of agricultural research. Examples are provided to (1) test for heterogeneity of the random interaction variance, and (2) to relate the usual orthogonal contrasts in a class GLM and their corresponding regression coefficients. The polynomial contrasts will be used to construct a response surface through adjusted treatment means. Finally, we present useful techniques to (3) perform a single degree of freedom test for interaction in a balanced unreplicated experiment (4) and to estimate residual (first-order 
carryover), direct, and permanent effects in designs balanced for residual effects and (5) coefficients to derive estimates of within and of between experimental units in a crossover experiment. In each case, an example is given in the appendixes.

\section{Heterogeneity of the Interaction Variance}

Often, the agricultural scientist wants to obtain valuable information about a product by repeating the same experiment in different sites or places. The idea is to recommend application of the product to a larger population of places or to measure the effect of varying external influences or conditions. Regardless the purpose of the experiment, the analysis of the results of such a series of experiments always presents statistical challenges. form:

The model that is commonly used to analyze such data is a mixed model of the

$$
\mathbf{Y}=\mathbf{X} \beta+\mathbf{Z} \boldsymbol{\mu}+\varepsilon
$$

where $\mathbf{X} \beta$ represents the fixed effects portion of the model, $\mathbf{Z} \boldsymbol{\mu}$ represents the random portion and $\varepsilon$ the residuals. One of the challenges when analyzing the data using model (1) with the GLM procedure of SAS is the assessment of the interaction magnitude contained in $\boldsymbol{\mu}$. More specifically, if a treatment made of 5 different levels of application, $0,40,80,120$ and 160 units is tested in 6 different places, the different sources of variation are: treatment (fixed effect of $\beta$ ), places and treatment*places (random effects of $\boldsymbol{\mu})$, and experimental error $(\varepsilon)$.

In many instances, it is necessary to test whether the components of the interaction treatment*places variance $\sigma_{1}^{2}$ are homogeneous i.e, $\sigma_{1}^{2}$ is a constant. One solution is to partition the interaction into components $\sigma_{1}^{2}, \sigma_{2}^{2}, \ldots, \sigma_{p}^{2}$ that extract all or almost all the useful information. This approach requires use of estimable functions. We use the example of Cochran and Cox $(1957$, p548) to illustrate the concept.

The orthogonal partition of the interaction is obtained by multiplying the vector of the full coefficients (extended to contain interaction terms) of treatment contrasts, $K_{\tau}$, with the full coefficients of the random effect contrasts, $K_{\mu}$. More specifically, in the example of Table $2, K_{\tau}$ represents the first four treatment contrasts (linear,quadratic and deviations contrasts), whereas $K_{\mu}$ represents the next four deviations denoted "Places ( $i$ last $)^{\prime \prime}$.

The resulting variances may be tested for their homogeneity in the usual manner. When the null hypothesis is rejected, i.e, the interaction variance is heterogeneous, then the component of the treatment sum of squares is tested against its own interaction with the random factor (Cochran and Cox, 1957; Kempthorne, 1952; Milliken and Ash, personal communication). 


\section{Orthogonal Contrasts and Regression Coefficients}

The types of experiments in which the application is simple are those resulting in balanced data with the treatment levels quantitative and equally spaced. It is possible to use combinations of the orthogonal polynomials to find the corresponding regression parameter estimates within the same run of GLM. The example used to illustrate the mechanics of relating dose levels defined as class variables to regression coefficients is from Steel and Torrie (1980, p366). The effect of five row spacings was tested on Ottawa Mandarin soybeans in six blocks of a randomized block design (Appendix $I_{a}$ ).

The mathematical expression of the two-way classification model is:

$$
\begin{aligned}
\mathrm{Y}_{\mathrm{ijk}} & =\mathrm{u}+\rho_{\mathrm{j}}+\alpha_{\mathrm{i}}+\varepsilon_{\mathrm{ijk}} \\
\mathrm{i} & =1,2, \ldots, \mathrm{t} ; \mathrm{j}=1,2, \ldots, \mathrm{r}
\end{aligned}
$$

where $u$ is the overall mean, $\alpha_{i}$ are unknown fixed parameters, $\rho_{\mathrm{j}}$ and $\varepsilon_{\mathrm{ijk}}$ are independent normally distributed random variables with zero mean and variances $\sigma_{\rho}^{2}$ and $\sigma_{\varepsilon}^{2}$, respectively. It is assumed that the ' $t$ ' treatment levels are equally spaced and there is one observation in each of the 'rt' cells. The null hypothesis of equal means is formulated as:

$$
\text { Ho: } \alpha_{1}=\alpha_{2}=\ldots=\alpha_{\mathrm{t}}
$$

When the null hypothesis is rejected at a specified alpha level, researchers typically investigate further for a linear and/or quadratic response in the data through the use of orthogonal contrasts. The question of relating the results of the contrasts to corresponding regression coefficients is often asked. A simple relationship between the linear trend and the regression coefficients can be formulated as:

$$
\begin{aligned}
& \mathrm{L}_{\beta 1}=\left(\lambda * \mathrm{C}_{\mathrm{i}}\right) /\left(\mathrm{d} * \Sigma \mathrm{C}_{\mathrm{i}}^{2}\right) \\
& \text { and } \mathrm{L}_{\beta \mathrm{O}}=\overline{\mathrm{Y}}-\overline{\mathrm{X}} * \mathrm{~L}_{\beta 1}
\end{aligned}
$$

where the values are either constants $(\lambda, d, \bar{X})$, easily estimable (the overall mean, $\bar{Y}$ ) or intrinsically estimable contrasts of the means or totals such as the orthogonal contrasts (see Table 15.11 of Steel and Torrie, 1980). Combinations of the coefficients $C_{i}$, in the manner of (2) and (3) result in $L^{*}=\left\{L_{\beta 0}, L_{\beta 1}\right\}$ such that $L^{*} \beta^{\circ}=\beta$ where $\beta^{\circ}$ is any solution of model (1) and $\beta=\left\{\beta_{o}, \beta_{1}\right\}$ is the vector of the regression coefficients. 
To illustrate the mechanics of above equations, the coefficients for $L_{\beta 0}$ and $L_{\beta 1}$ are derived for the soybean example:

\begin{tabular}{|c|c|c|c|c|c|c|c|c|c|c|c|c|c|}
\hline \multirow[t]{2}{*}{ Effect Parameter } & $\begin{array}{l}\mathrm{I} \\
\mathrm{n} \\
\mathrm{t} \\
\mathrm{e}\end{array}$ & \multicolumn{6}{|c|}{ Block } & \multicolumn{5}{|c|}{ Spacing } & $\begin{array}{l}\mathrm{D} \\
\mathrm{i} \\
\mathrm{v} \\
\mathrm{i}\end{array}$ \\
\hline & $\begin{array}{l}\mathrm{r} \\
\mathrm{c} \\
\mathrm{e} \\
\mathrm{p} \\
\mathrm{t}\end{array}$ & I & II & III & IV & V & VI & I & II & III & IV & V & $\begin{array}{l}\mathrm{S} \\
\mathrm{o} \\
\mathrm{r}\end{array}$ \\
\hline $\mathrm{L}_{\beta 1}=\mathrm{C}_{\mathrm{i}}$ & 0 & 0 & 0 & 0 & 0 & 0 & 0 & -2 & -1 & 0 & 1 & 2 & 60 \\
\hline $\bar{Y}=$ mean yield & 60 & 10 & 10 & 10 & 10 & 10 & 10 & 12 & 12 & 12 & 12 & 12 & 60 \\
\hline$\overline{\mathrm{X}} * \mathrm{~L}_{\beta 1}=30 * \mathrm{~L}_{\beta 1}$ & 0 & 0 & 0 & 0 & 0 & 0 & 0 & -60 & -30 & 0 & 30 & 60 & 60 \\
\hline $\mathrm{L}_{\beta 0}=\overline{\mathrm{Y}}-\overline{\mathrm{X}}^{*} \mathrm{~L}_{\beta 1}$ & 60 & 10 & 10 & 10 & 10 & 10 & 10 & 72 & 42 & 12 & -18 & -48 & 60 \\
\hline
\end{tabular}

The divisor of $\mathrm{L}_{\beta 1}$ is $\mathrm{d}^{*} \Sigma^{5}{ }_{1} \mathrm{C}_{\mathrm{i}}=6^{*}(4+1+0+1+4)=60$. The values of $\lambda, \mathrm{d}, \overline{\mathrm{X}}$ are 1,6 , and 30 , respectively. To compute $\mathrm{L}_{\beta 0}$, mathematical operations between vectors are performed on coefficients within the same parameter. Appendices $\left(\mathrm{I}_{\mathrm{a}}\right)$ and $\left(\mathrm{I}_{\mathrm{b}}\right)$ provide the derivation of $L^{*}$ for various response surfaces from the simplest with one dependent variable $\left(I_{a}\right)$ to the complex with two variables, including their quadratic and interactions terms $\left(I_{b}\right)$. The details that lead to these coefficients can be obtained from the first author.

\section{Tukey's single-degree-of-freedom test}

The basic idea of Tukey's test is to evaluate the merit of adding an interaction term in a model of main effects when no replicate is available (Tukey, 1949). It is based on partitioning the experimental error of the additive model

$$
Y=\mu+\tau_{i}+\beta_{j}+\gamma_{i j}
$$

with no interaction into two components, one associated with nonadditivity sum of squares (SSN) and another associated with the remaining sum of squares (SSR).

The traditional approach requires many runs of GLM (Shiferaw and Griffin, 1986). With the use of estimable functions, the number of steps is reduced to two. First, from the additive model, one needs to derive a new solution vector that satisfy the sum-to-zero restriction on the parameters instead of the default set-to-zero restriction. The solution given by the GLM procedure has the last parameter set-to-zero $\left(\tau_{\text {last }}=0\right.$ and $\beta_{\text {last }}=0$ ). To convert it to a sum-to-zero solution, each $\tau_{i}$ and each $\beta_{j}$ are assigned an integer, say 1 , and the others are assigned an equal weight, $-1 /(\mathrm{t}-1)$, and $-1 /(\mathrm{b}-1)$ respectively such that $\Sigma \tau_{i}=0$ and $\Sigma \beta_{j}=0$.

The next step is to merge the new column estimates, say $\tau^{*}$ and $\beta^{*}$, by each of the 
two factors, with the existing data and run a covariance analysis with the product of the two columns $\tau^{*} \beta^{*}$ as the covariate. The test for the covariate is the Tukey's single-degreeof-freedom for non-additivity. The data for this example are from Milliken and Johnson (1989) and are reported in Appendix II.

\section{Estimation of direct, residual, and permanent effect}

Crossover trials are frequently used by researchers from many fields. In experiments with residual effects, partial confounding exists between effects in the model. Consequently, in the case of a model that contains all class effects, using LSMEANS statement within GLM results in non-estimability of the fixed effects. This is especially true for overparameterized models which do not yield a unique solution but rather a biased vector based on the default set-to-zero restrictions on certain (last) parameters. In this instance the use of estimable functions with appropriate coefficients (see appendix $\mathrm{III}_{\mathrm{a}}$ ) leads to appropriate treatment comparisons since the expected difference between any two treatments contains a component associated with the residual difference of the same effects. Kempthorne (1957) stated that this comparison is the sole advantage of balancing with regard to the preceding treatment since "we are not measuring a linear combination of the direct effects of one treatment and the residual effects of the others." Another common method that also relies on restrictions imposed on the elements of the parameter vector is the sum-to-zero restrictions. This method yields a full rank model (see appendix $\mathrm{III}_{\mathrm{b}}$ ).

$\Lambda$ third alternative for estimating the parameters of interest is to combine the previous two, generally by restricting only the (class) residual to sum-to-zero. This method is easier to implement, it allows the LSMEANS statement to be estimable for the direct effects, and therefore does not require to provide own coefficients, and at the same time provides correct carryover differences as slopes in the solution vector (see appendix III $_{c}$ ). The data used to illustrate the example is from Cochran and Cox (1957 p135). Three rations were tested for their effects on fat corrected milk yield. The milk was collected from each cow at the end of a six week period. The basic design was an orthogonal $3 \times 3$ latin square. Cows were assigned to square based on their preliminary production: cows with similar corrected milk production were grouped in sequence of three. Then within each sequence, a randomly chosen square had its columns randomly assigned to cows. Three different statistical models were used according to the restrictions on the model parameters.

\section{Estimates of within and between carryover differences}

When carryover designs use two sizes of experimental units (EU), two error terms, and two levels of analysis (between and within EU), the GLM procedure of SAS fails to provide an adequate analysis. Among the three possible estimates of carryover differences, two of them, the within and the between differences can easily be obtained within GLM. The estimates of the within experimental unit are obtained as in the section described above (Section 4). 
The estimates of the between experimental unit carryover differences are obtained by comparison of whole size ( $E U$ ) means. For illustration purpose, we use the data from a three-period crossover design with three treatments (Milliken and Johnson, 1984 p447). The statistical model includes sequence effect $(\alpha)$, experimental unit within sequence $(\eta)$, treatment effect $(a, b$, and $c)$, carryover effect $(\Phi)$, period effect $(\Pi)$ and the residuals $(\varepsilon)$.

To obtain the between-experimental-unit estimates of carryover differences, one needs to fit the experimental unit mean model. It follows that the estimates of the carryover difference between, say $\Phi_{\mathrm{a}}$ and $\Phi_{\mathrm{c}}$, is given by

$$
\Phi_{\mathrm{a}}-\Phi_{\mathrm{c}}=\left\{\left(\alpha_{1}+\alpha_{3}\right)-\left(\alpha_{4}+\alpha_{6}\right)\right\} * 3 / 2
$$

Since each sequence mean is estimable, by the rule of combination of estimable functions, $\Phi_{a}-\Phi_{c}$ is also estimable (Searle 1971, 1987). Other comparisons can be made in a similar fashion (see Table 1 and appendix IV). It remains however, that if the coefficients lead to estimability for the entire model including the random effect, then the standard-error of the between difference will be based solely on the estimated MSE, $\sigma_{\varepsilon}^{2}$ instead of the estimate of $\sigma_{\varepsilon}^{2}+\sigma_{\eta}^{2}$.

One solution is to utilize the mixed model procedure, PROC MIXED of SAS where the RANDOM statement is used to specify the random portion of the model. The coefficients corresponding to the random effects in each ESTIMATE statement will be assigned to zero automatically (broad inference space). The narrow inference space standard error is .708. The broad inference space standard error is 2.27 (Milliken and Jonhson, 1984, give a standard error of 2.34).

Authors Note: Copies of SAS output for all examples can be requested from Dr. Louis Munyakazi, Monsanto Company, Mail Zone BB2D, 700 Chesterfield Village Parkway, St. Louis, Mo. 63198. 


\section{Referrences}

Cochran, W.G., Autrey, K.M, and Cannon, C.Y. (1941). A double change-over design for dairy cattle feeding experiments. Jour. Agr. Sci. 24 937-951.

Cochran, W.G. and Cox, G.M. (1957). Experimental Designs $2^{\text {nd }}$. New York: John Wiley \& Sons.

SAS Institute Inc. SAS ${ }^{\circledR}$ SAS/STAT ${ }^{\circledR}$ User's Guide, Version 6, Fourth Edition, Volume 1-2, Cary, NC: SAS Institute Inc. 1989. pg. 943.

Milliken, G.A. and Johnson, D.E. (1984). Analysis of Messy Data. Vol I: Designed Experiments. Van Nostrand Reinhold Co. Inc., New York.

Steel, R.G.D, and Torrie, J.H. (1980). Principles and Procedures of Statistics. A Biometrical Approach. New York. McGraw_Hill Book Co.

Little, Joyce.E., Milliken, G.A. and Schwenke, J.R. (1988). The Analysis of Williams Square Designs with Several Subjects per Sequence. Proceedings of the Biopharmaceutical Section, American Statistical Association, New Orleans, 232234.

McLean, R.A. Sanders, W.L and Stroup, W.W. (1991). A Unified Approach to Mixed Linear Models. The American Statistician 45, 54-64.

Munyakazi, L, Hintz R.L. and Selby,B.D. (1995). Estimation of Direct, Residual and Permanent Effects in Designs Balanced for Residual Effects in the GLM. Observations $^{\circledR}$. The Technical Journal for SAS Software users (in press).

Searle, S.R. (1971). Linear Models, New York: John Wiley \& Sons.

Searle, S.R. (1987). Linear Models for Unbalanced data, New York: John Wiley \& Sons.

Milliken, G.A. and Ash, K.A.. An Investigation of the Effects of Heterogeneity of Variance on the Combined Analysis of Data From Several Experiments (personal communication).

Kempthorne, O (1952). The design and Analysis of Experiments. A Wiley Intl. Ed.

Tukey, J.W (1949). One degree of Freedom for Non-additivity. Biometrics 5:232-242.

Shirferaw, G.M and Griffin, D.W (1986). One degree of freedom for transformable nonadditivity- A generalized SAS macro. in the Preceeding of SAS Users Group International. Eleventh Annual Conference. Atlanta, Georgia. February 9-12, 1986. 
Table 1. Coefficients of between carryover differences in the sequence model.

\begin{tabular}{|c|c|c|c|}
\hline \multirow[b]{2}{*}{ Sequence Model } & \multicolumn{3}{|c|}{ Between Differences } \\
\hline & $\Phi_{\mathrm{a}}$ vs $\Phi_{\mathrm{b}}$ & $\Phi_{\mathrm{a}}$ vs $\Phi_{\mathrm{c}}$ & $\Phi_{\mathrm{b}}$ vs $\Phi_{\mathrm{c}}$ \\
\hline$\alpha_{1}=\delta^{*}+1 / 3\left(\Phi_{\mathrm{a}}+\Phi_{\mathrm{b}}\right)$ & 0 & 1.5 & 1.5 \\
\hline$\alpha_{2}=\delta^{*}+1 / 3\left(\Phi_{\mathrm{a}}+\Phi_{\mathrm{c}}\right)$ & 1.5 & 0 & -1.5 \\
\hline$\alpha_{3}=\delta^{*}+1 / 3\left(\Phi_{\mathrm{a}}+\Phi_{\mathrm{b}}\right)$ & 0 & 1.5 & 1.5 \\
\hline$\alpha_{4}=\delta^{*}+1 / 3\left(\Phi_{b}+\Phi_{c}\right)$ & -1.5 & -1.5 & 0 \\
\hline$\alpha_{5}=\delta^{*}+1 / 3\left(\Phi_{\mathrm{a}}+\Phi_{\mathrm{c}}\right)$ & 1.5 & 0 & -1.5 \\
\hline$\alpha_{6}=\delta^{*}+1 / 3\left(\Phi_{b}+\Phi_{c}\right)$ & -1.5 & -1.5 & 0 \\
\hline
\end{tabular}


Table 2. Coefficients for TREAT*PLACES Variance Interaction Test

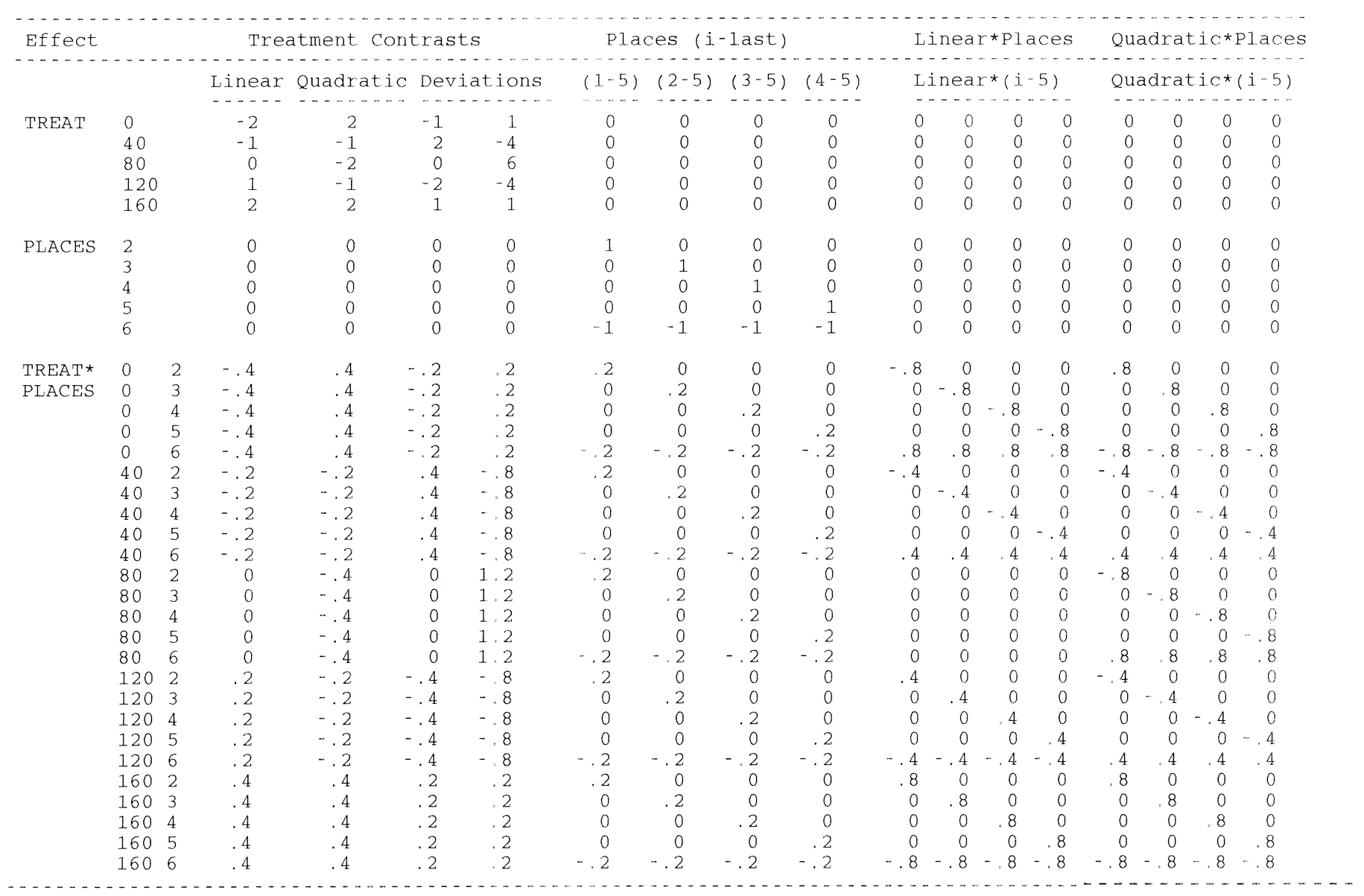




\section{Appendix $I_{a}$}

Titie 'Data is from Steel and Torrie 2 nd Ed. $p 366$ '
Form of the equations: $Y=\beta_{0}+\beta_{1} X$ and $Y=\beta_{0}+\beta_{1} X+\beta_{2} X^{2}$
$(X=$ spacing)

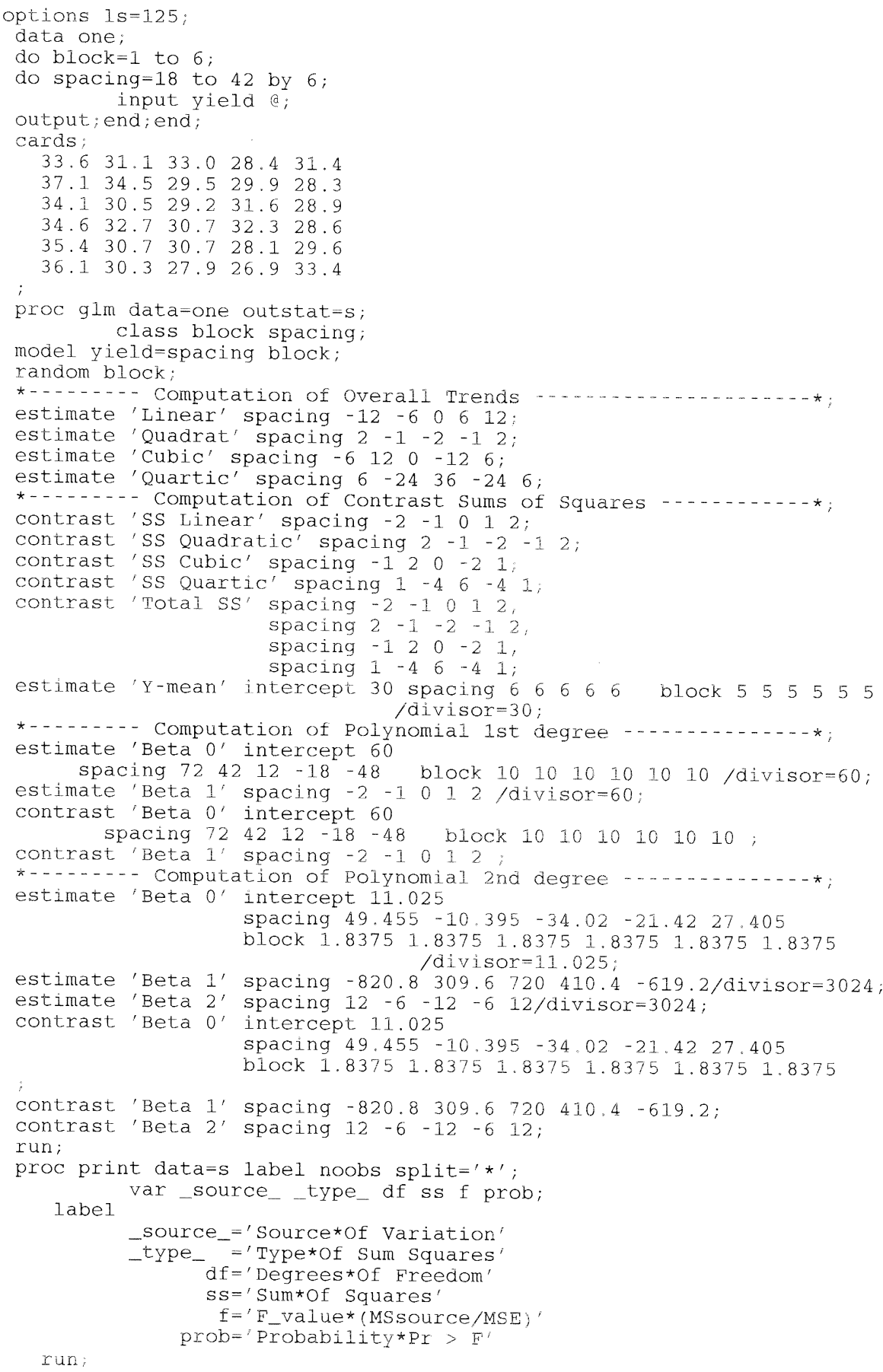




\section{Appendix $I_{b}$}

*- - Construct a response surface through the treatment means

*- using the concept of estimable functions within GLM procedure

*- This is an extension of the second degree curve through the means

Form of the equation: $Y=\beta_{0}+\beta_{1} X_{1}+\beta_{2} X_{1}^{2}+\beta_{3} X_{2}+\beta_{4} X_{2}+\beta_{4} X_{2}^{2}+\beta_{5} X_{1} X_{2}$ $\left(X_{1}=\right.$ rates and $X_{2}=$ days $)$

data one; input Days Rates

do blocks=1 to 4

input shoots

cards ;

output; end;

$\begin{array}{llllllll}3 & 0 & 15.7 & 14.6 & 16.5 & 14.7\end{array}$

$\begin{array}{rrrrrr}3 & 4 & 9.8 & 14.6 & 11.9 & 12.4 \\ 3 & 8 & 7.9 & 10.3 & 9.7 & 9.6\end{array}$

$\begin{array}{llllll}10 & 0 & 18.0 & 17.4 & 15.1 & 14.4\end{array}$

$\begin{array}{lllllll}10 & 4 & 13.6 & 10.6 & 11.8 & 13.3\end{array}$

$\begin{array}{lllllll}10 & 8 & 8.8 & 8.2 & 11.3 & 11.2\end{array}$

proc glm; class rates days blocks

model shoots=blocks rates*days

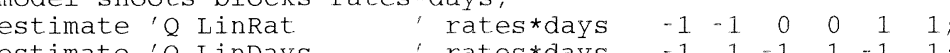

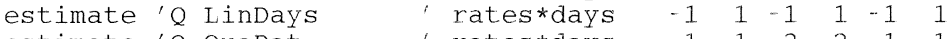

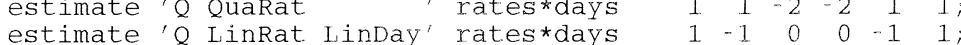

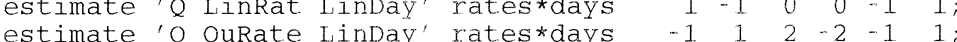

estimate, Coeficient B5, rates*days $-1 \quad 1 \quad 2-2-1$ 1/divisor $=224$

estimate, Coeficient B4, rates*days $3-3-4 \quad 4 \quad 1-1 /$ divisor $=56$;

estimate, Coeficient B3, rates*days $-6 \quad 6 \quad 00000 /$ divisor $=42$

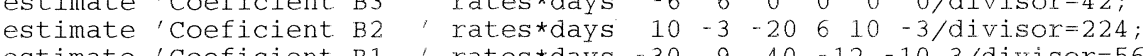

estimate 'Coeficient B1, rates*days $\begin{array}{cccccccc}-30 & 9 & 40 & -12 & -10 & 3 & \text { /divisor }=56\end{array}$

estinate coeficient Bo intercept 84 blocks 21212121 . 21 .

titlel 'Estimable functions and Response Surface', 


\section{Appendix II}

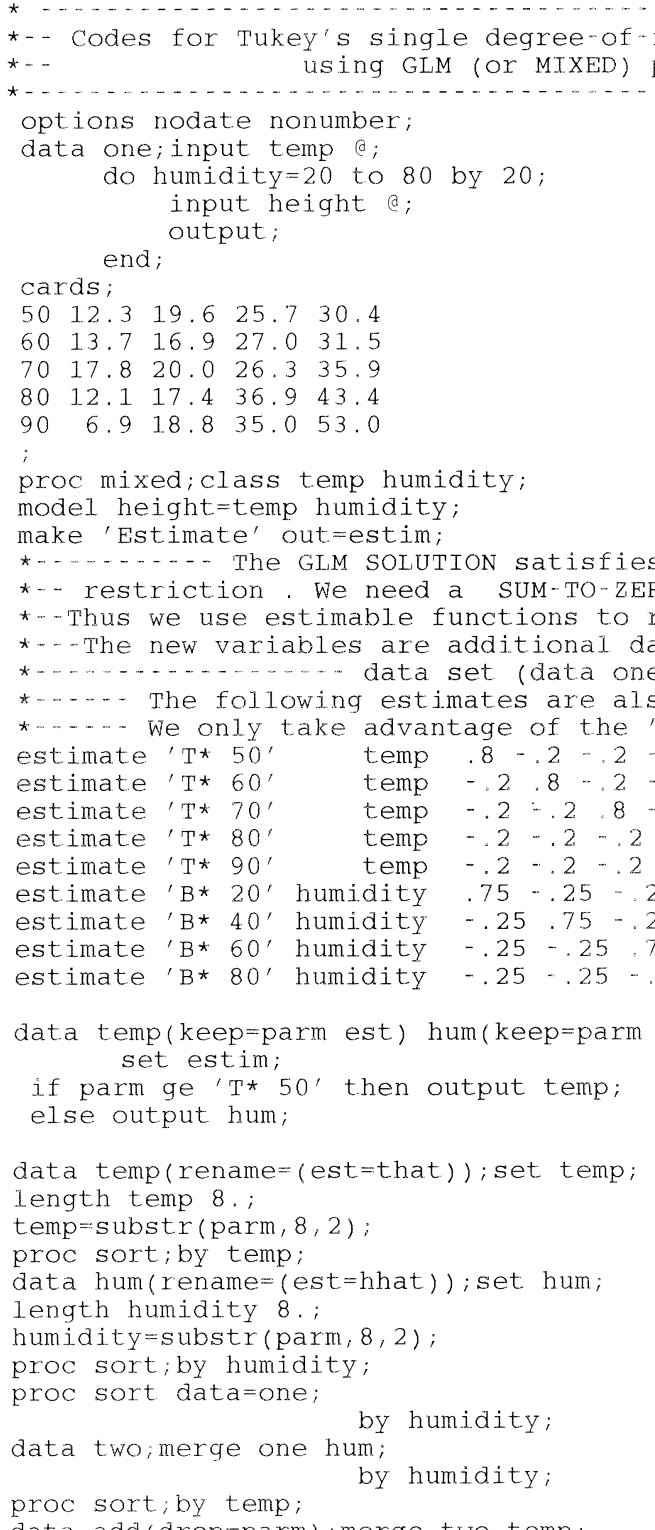

data add(drop=parm); merge two temp;

\section{New Prairie Press}

https://newprairiepress.org/agstatconference/1994/proceedings/21 
by temp;

proc glm; class temp humidity,

model height=temp humidity that*hhat/ss1 ss2 ss3 ss4;

estimate I estimate, That*hhat 1 ;

contrast 'SSN Non Add That*hhat 1

Titlel' Tukey''s single degree-of-freedom test for non-additivity';

proc glm; class temp humidity;

model height=temp humidity that*humidity/ss3

estimate 'Mean THAT*Humidity' that*humidity $.25 \quad 25 \quad 25-.75$

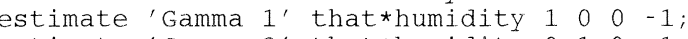

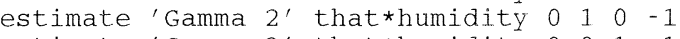

estimate 'Gamma 3' that*humidity $00001-1$,

estimate 'Estimate Gamma1' that*humidity $.75-.25-.25-.25$;

estimate 'Estimate Gamma2' that*humidity - $-.25 \quad .75-.25-.25$;

estimate 'Estimate Gamma3', that *humidity $-.25-.25-.75-.25$;

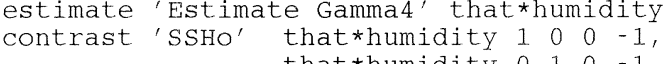
$\begin{array}{lllll}\text { that*humidity } & 0 & 1 & 0 & -1 \\ \text { that } & -1 \\ \text { humidity } & 0 & 0 & 1 & -1\end{array}$

Titlel 'Mandel''s test of interaction. Lines for each level Humidity'

Title2 'That is Mandel''s model with Temperature as the Baseline'

model height=temp humidity hhat*temp/ss3

$2.2-.8$

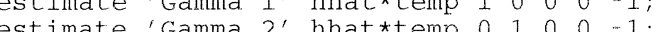

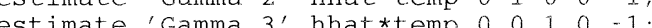

estimate, Gama 3 , hhat *temp 0000

estimate 'Estimate Gamma1' hhat *temp $.8-.2-.2-.2-.2$;

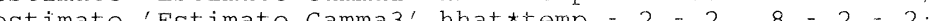

estimate 'Estimate Gamma4' hhat temp - $-2 \quad-.2 \quad-.2 \quad 8 \quad-.2$;

estimate 'Estimate Gamma5' hhat*temp-2 - $2-2-2,8$;

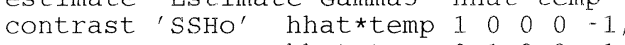

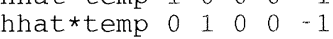

hhat * temp $0000100-1$

hhat *temp $00 \begin{array}{lllll}0 & 0 & 1 & -1\end{array}$

Titlel 'Mandel''s test of interaction. Lines for each level Temperature'

Title2 'That is Mandel''s model with Humidity as the Baseline'

*........ Comparison between Tukey's and Mandel's tests ..........

proc glm; class temp humidity;

model height=temp humidity that*hhat temp*hhat/ss 3

titlel 'Comparison between Tukey''s and Mandel''s tests';

title2 


\section{Appendix III}

Codes for Estimation of Direct Residual and Permanent Effects in GLM

$$
\text { Data are from Cochran and Cox } 1957 \text { (p135)' }
$$

proc glm; class square trt cow period resid;

model milk=square cow(square) period(square) trt resid/ss3 solution

estimate 'Direct 1 ' intercept 18 square 99 cow(square) $\begin{array}{lllllllllll}3 & 3 & 3 & 3 & 3 & 3\end{array}$

period(square) $\begin{array}{lllllllllllll} & 3 & 3 & 3 & 3 & 3 & \text { trt } 18 & 0 & 0\end{array}$

resid $6 \quad 4 \quad 4 \quad 4$ /divisor $=18$

estimate 'Direct 2 ' intercept 18 square $9 \quad 9$ cow(square) $\begin{array}{lllllll}3 & 3 & 3 & 3 & 3 & 3\end{array}$ period(square) $3 \begin{array}{llllllllll}3 & 3 & 3 & 3 & 3 & \text { trt } 0 & 18 & 0\end{array}$ resid $6 \begin{array}{lll}6 & 4 & 4 \\ \text { /divisor }=18\end{array}$

estimate 'Direct 3' intercept 18 square 99 cow(square) $\begin{array}{llllll}3 & 3 & 3 & 3 & 3 & 3\end{array}$

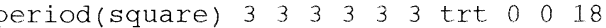
resid $6 \begin{array}{lll}6 & 4 & 4 \\ \text { /divisor }=18\end{array}$

estimate 'Residu (1+Mean)'intercept 18 square 99 cow(square) 3333333 period(square) $3 \quad 3 \quad 3 \quad 3 \quad 3 \quad 3$ trt $6 \quad 6 \quad 6$ resid $61200 /$ divisor $=18$

estimate 'Residu (2+Mean)'intercept 18 square 99 cow(square) 333333 period(square) $3 \begin{array}{lllllllll}3 & 3 & 3 & 3 & 3 & \text { trt } & 6 & 6 & 6\end{array}$ resid $6 \quad 0 \quad 12$ o/divisor $=18$

estimate 'Residu (3+Mean)'intercept 18 square 99 cow(square) $\begin{array}{llllll}3 & 3 & 3 & 3 & 3\end{array}$ period(square) 3 3 33 3 33 trt 6 6 6 resid 6 o 0 12/divisor $=18$

estimate 'Overall Mean' intercept 18 square 99 cow(square) $\begin{array}{llllll}3 & 3 & 3 & 3 & 3\end{array}$ period(square) 3333333 trt 666 resid 6 4 4 a 4 aivisor $=18$

estimate 'Residu 1 alone resid $0 \quad 12-6 \quad-6 /$ divisor $=18$

estimate "Residu 2 alone resid 0 - -6 - 12 - $-6 /$ divisor $=18$;

estimate 'Residu 3 alone resid 0 - 6 - -6 r $12 /$ divisor $=18$;

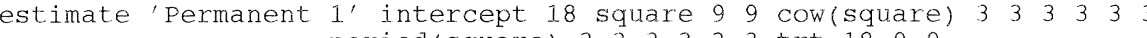
period(square) 3 s 3 3 3 3 trt resid $6 \quad 16-2-2 /$ divisor $=18$

estimate 'Permanent 2 ' inter period(square) $3 \begin{array}{llllll}3 & 3 & 3 & 3 & \text { trt } 0 & 18\end{array}$

resid $6-216-2 /$ divisor $=18$

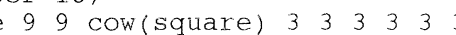
period(square) $\begin{array}{lllllllll}3 & 3 & 3 & 3 & 3 & \text { trt } 0 & 0 & 18\end{array}$ resid $6-2-2$ 16/divisor $=18$

estimate 'Perm $1-2$ ' 1 (rt $18-2-18$

estimate 'Direct(1-2)-Res(1-2)' trt $18-18$ o resid 0 18-18 $0 /$ divisor=18; 
Appendix $\operatorname{III}_{\mathrm{b}}$

CODES FOR SUM-TO-ZERO RESTRICTIONS

proc glm

model milk=seq1 cow1 cow2 cow 4 cow5 per1 per2 per4 per5 trt1 trt

resid1 resid2/solution;

estimate overal1, intercept 18 seq1 9 cow1 3 cow2 3 cow4 3 cow5 per1 3 per2 3 per4 3 per5 3 trt1

(1)

estimate 'Direct $1^{\prime} \quad$ intercept 1 trt 1

estimate 'Direct 2' intercept 1 trt2 1;

estimate Direct 3 , intercept 1 trt 1

estimate Direct $1-2$ trt 1 trt2 -1 ;

estimate Direct $1-3$, trt 12 trt. 1 i

estimate Direct 2 - 3 ' trt 1 1 trt $22^{2}$

estimate Residu 1 ' residi 1

estimate 'Residu 3' resid1-i resid2 -1;

estimate 'Res 1 - 2 ' residl 1 resid2 - 1

estimate 'Res $1-2^{\prime}$ residl 1 resid2 1 ;

estimate Res $2-3^{\prime}$ residi 1 resid2 2 ;

stimate permanent 1 ' intercept $1 \operatorname{trt} 1$ residi 1

estimate 'Permanent 3 , intercept 1 trt1 - 1 trt2 - 1 resid1 - 1 resid2 - 1 ;

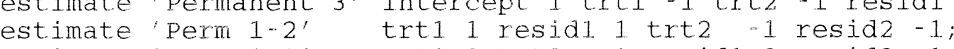

estimate 'Perm 1-3' trt1 2 trt2 1 resid1 2 resid2 1 


\section{Appendix III}

CODES FOR COMBINATTON OE SET-TO-ZERO \& SUM-TO-ZERO RESTRTCTIONS

proc sort; by cow;

data two; set one;

resid $1=0$

resid $1=0$
resid $2=0$

if period ne 1 then do:

if last $\operatorname{trt}=1$ then resid $1=1$

if last $\operatorname{trt}=2$ then resid $2=1$

if last trt $=3$ then do:

$$
\begin{gathered}
\text { resid } 1=-1 ; \text { resid } 2=-1 ; \\
\text { end } \text { end ; }
\end{gathered}
$$

last_trt=trt

drop last_trt persqu

titlel 'sum-to-zero contraints on the residual effect'

title2 'Set-to-zero contraints on the other effects'

title3 'This corresponds to an analysis of covariance',

proc glm; class square trt cow period

model milk=square cow(square) period(square) trt resid1 resid2/solution

smeans trt; * Direct effects are estimable;

stimate Residu l' resid $1_{i}$

estimate 'Residu 2

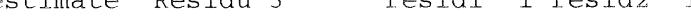

estimate 'Residu $1-3$ ' residi 2 resid2 ${ }^{-1}$ i

estimate 'Residu 2 - 3' residl 1 resid2 2 '

contrast 'Carryover SS' resid1 2 resid2 1, resid1 1 resid2 2, 


\section{Appendix IV}

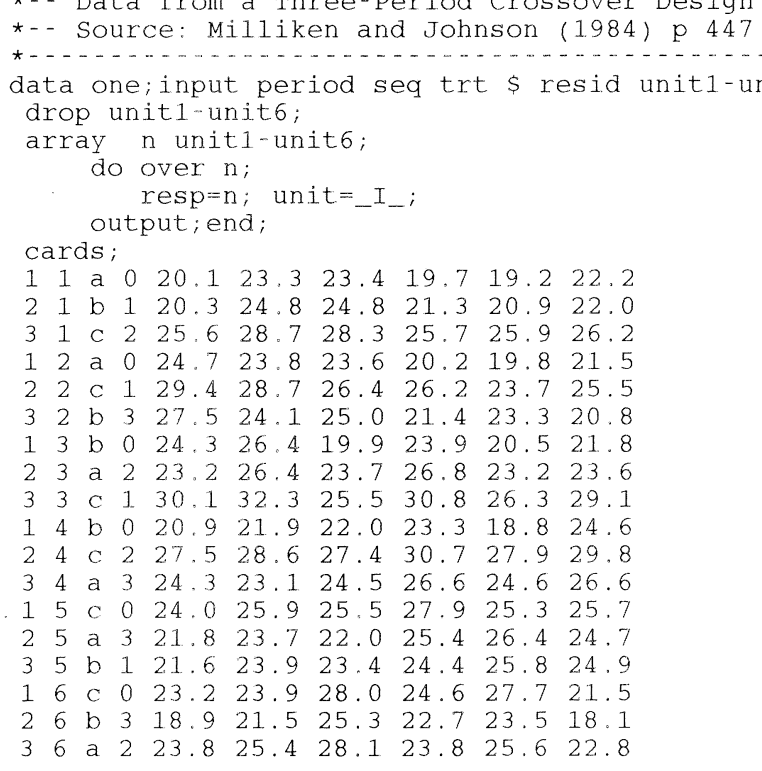


*... Differences between 'sequences' represent $2 / 3$ of the actual ..... *... carryover or residual difference ...... *-.. Then the desired differences are $3 / 2$ times seq

$$
\begin{array}{rllllllllllllllllll}
\text { unit (seq) } & 0 & 0 & 0 & 0 & 0 & 0 & 3 & 3 & 3 & 3 & 3 & 3 & 0 & 0 & 0 & 0 & 0 & 0 \\
-3 & -3 & -3 & -3 & -3 & -3 & 3 & 3 & 3 & 3 & 3 & 3 & -3 & -3 & -3 & -3 & -3 & -3
\end{array}
$$$$
\text { resid } 0 \begin{array}{lll} 
& 12 & -1
\end{array}
$$

divisor $=12$

estimate 'Between Resid A-C' seq 18 C

$\begin{array}{ccccccccccccccccccc}\text { unit( (seq) } & 3 & 3 & 3 & 3 & 3 & 3 & 0 & 0 & 0 & 0 & 0 & 0 & 3 & 3 & 3 & 3 & 3 & 3\end{array}$

$\begin{array}{lllllllllllllllllllll}-3 & -3 & -3 & -3 & -3 & -3 & 0 & 0 & 0 & 0 & 0 & 0 & -3 & -3 & -3 & -3 & -3 & -3\end{array}$ resid $0 \begin{array}{lllll} & 12 & 0 & -12\end{array}$

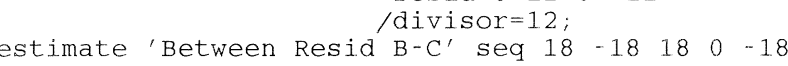

unit (seq) $3 \begin{array}{lllllllllllll}3 & 3 & 3 & 3 & 3 & -3 & -3 & -3 & -3 & -3 & -3\end{array}$

$\begin{array}{llllllllllllllll}3 & 0 & 0 & 0 & 0 & 0 & 0 & -3 & -3 & -3 & -3 & -3 & -3\end{array}$

resid $0 \begin{array}{lllll} & 0 & 12 & -12\end{array}$

/divisor $=12$ 